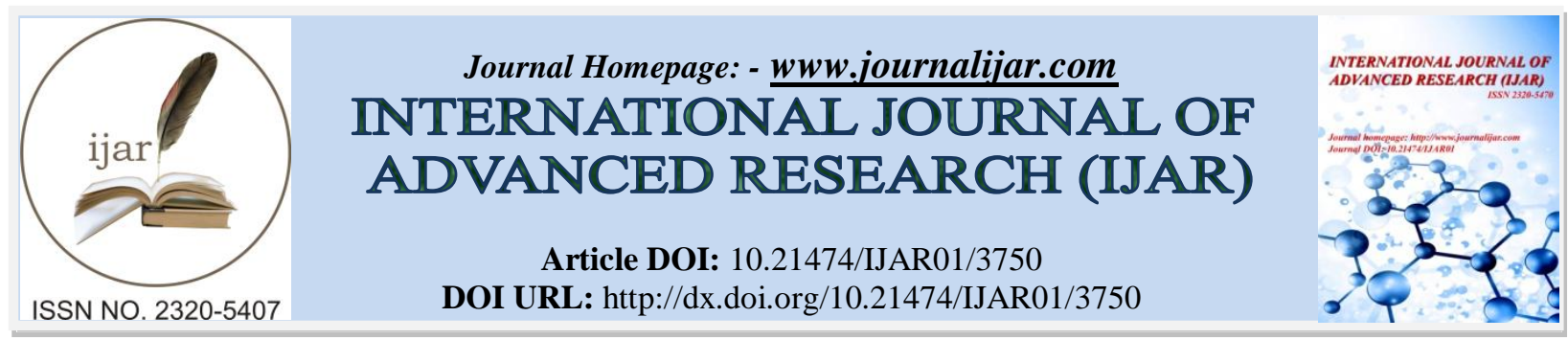

RESEARCH ARTICLE

\title{
EXPLOITATION OF RIB CARTILAGE IN SEPTORHINOPLASTY IN PRIMARY AND REVISION CASES AT KING ABDULLAH MEDICAL CITY (KAMC).
}

\section{Mohammed Saad Aly, Alhareth Adnan Baarimah, Omar Abdullah Qudos and Redwan Anwar Khan.}

\section{Manuscript Info}

Manuscript History

Received: 16 January 2017

Final Accepted: 05 February 2017

Published: March 2017

\section{Abstract}

Background: Rhinoplasty is one of the most popular cosmetic procedures in all over the world. Rib cartilage graft is used as an alternative to septum cartilage, with the advantage of providing sufficient amount of cartilage even for primary or revision Rhinoplasty. In this study, we will use rib cartilage graft in primary and revision Rhinoplasty cases. The rib cartilage graft will be obtained from different anatomical sites, depending on patient gender while using different techniques. The patient nasal angles and lines will be measured before and after the operation with recording the patient satisfaction in functional and cosmetic manners.

Methodology: Reconstruction Rhinoplasty cases performed from January 2011 to December 2016 were chosen from the King Abdullah Medical Center KAMC in Saudi Arabia. A total of 18 patients (10 females and 8 male) were selected from ENT clinic, with the age above 18 years and all of which must presented with nasal deformity and nasal obstruction. Patients Seeks for cosmetic Rhinoplasty was excluded from our study. Rib cartilages were used in all patients as the graft of choice for the Rhinoplasty procedure and different technique were used as well.

Results: A total of 18 cases; $8(44.4 \%)$ male patients, $10(55.6 \%)$ female patients, All of them are Middle East patients. They are presented with different nose presentation, majority of them had dorsal saddling (77.8\%) and deviated nose (66.7\%). and they are complaining of poor breathing and Aesthetic look.

Regarding the nasal angles (Nasofrontal, Nasolabial angle, and Tip deviation) have been measured pre and post-operative as well. And for all the angles, their P Values are statistically significant.

Pre-op Nasofrontal angle, Mean \pm SD (144.4 \pm 7.9). Post-op Nasofrontal angle, Mean \pm SD $(135 \pm 7.8)$. $\mathrm{P}$ value is $<0.001$ which is significant. Pre-op Nasolabial angle, Mean \pm SD $(86.4 \pm 9.5)$. Post-op Nasolabial angle, Mean \pm SD $(97.9 \pm 7.7)$. $\mathrm{P}$ value is $<0.001$ which is significant. Pre-op tip deviation, Mean \pm SD $(1.9 \pm 2.3)$. Post-op tip deviation, Mean \pm SD $(0.47 \pm 0.73)$.

Conclusion: We conclude that autogenous rib cartilage grafts are an outstanding material in septorhinoplasty when structural, functional, and aesthetic problems are present. 
Autogenous rib cartilage grafts are the gold standard for nasal reconstruction in patients with cartilage depletion and when large amount of cartilage are needed.

Copy Right, IJAR, 2017,. All rights reserved.

\section{Introduction:-}

Rhinoplasty is one of the most popular cosmetic procedures in all over the world. However, nowadays autografts is preferred, mainly due to less complication when compared to other types of grafts.

Cartilage grafts usually obtained from septum and costal cartilage. The size of the required graft and the type of the procedure (either primary or revision Rhinoplasty) usually determine the site of where the graft is taken. In small graft, the septum cartilage is considered the graft of choice. But in reconstruction or revision procedures, the use of septum cartilage is limited because it is either too small or it because it removed from previous operation [1, 2, 6].

Rib cartilage graft is used as an alternative to septum cartilage, with the advantage of providing sufficient amount of cartilage even for primary or revision Rhinoplasty. Complains about the rib graft has been introduced and different techniques have been suggested to improve rib graft results [2, 4].

The 5th or 9th rib cartilage is the site of choice in female or male respectively in dorsal augmentation and reconstructive support in general. Especially in secondary Rhinoplasty because there is not sufficient septal conceal cartilage $[1,2]$.

Numbers of factors make Secondary Rhinoplasty more difficult than the primary cases. Rhinoplasty considered one of the most challenging surgeries, and it has a revision rate of $21 \%$ [3].

In this study, we will use rib cartilage graft in primary and revision Rhinoplasty cases. The rib cartilage graft will be obtained from different anatomical sites, depending on patient gender while using different techniques. The patient nasal angles and lines will be measured before and after the operation with recording the patient satisfaction in functional and cosmetic manners.

\section{Methodology:-}

The cases presented from January 2011 to December 2016 were chosen from the ENT department at King Abdullah Medical City, Makkah, Saudi Arabia. A total of 18 patients from 250 septorhinoplasty cases (10 females and 8 male) were selected from ENT clinic retrospectively with consent obtained before starting, and IRB approval was taken.

\section{Inclusion criteria:-}

The age above 18 years, and presented with nasal deformity and obstruction. Both primary and revision SeptoRhinoplasty cases were included.

All patients have been examined before and after the operation, and all complains were documented as well. The measurements of the Nasal lines and angles were obtained from patients pictures. The patient's satisfactions from breathing and aesthetic point of view pre and post operative estimated by using Likert Scale from 1 to 5 ( $1=$ not satisfied) and ( 5 = completely satisfied).

Post operatively the patients observed for complication and recorded if existed, then the follow up continued until one year at least after the procedure and all the measurements and data were obtained.

Costal cartilage is the graft of choice when there is no preserved septal or conchol cartilage in the Septorhinoplasty in both revision and primary severely depressed nose. Costal cartilage harvested from the $9^{\text {th }}$ rib in male patients while in female patients was taken from the $5^{\text {th }}$ rib just above the infra mammary fold to obscure the appearance of the scar.

Two techniques had been applied to the harvested costal cartilage:

$1^{\text {st }}$ is the core of the rib was used as a spreader and strong strut graft and the outer part of the cartilage was diced and wrapped with either rectus fascia or temporalis fascia (16 cases),

$2^{\text {nd }}$ technique slanting incision was done to form straight slices which used as spreader and strut graft and the remnant was diced and wrapped in rectus fascia ( 2 cases). 


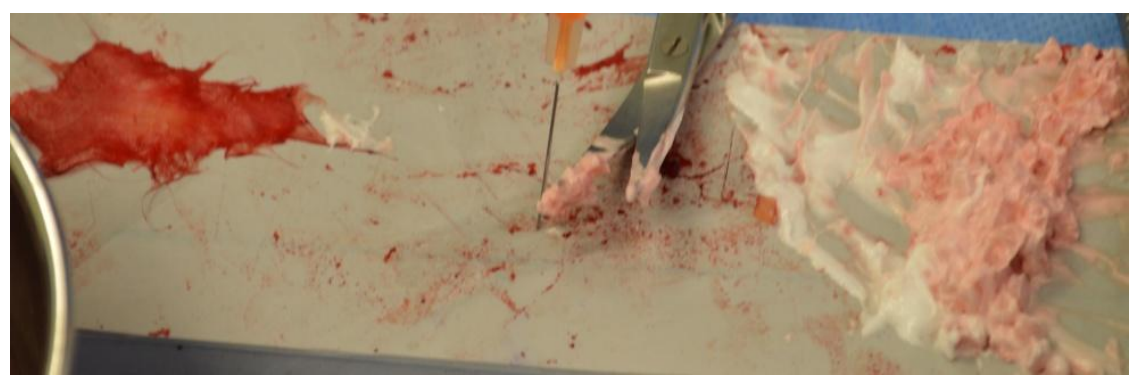

\section{Diced Rib Cartilage Graft Wrapped in Rectus Fascia:-}

The surgeon isolate and separate the rectus muscle fascia and remove any remnant of fat or muscles and spread it on the table and then compress it to be more thinner and its measure about $(6 \times 6 \mathrm{Cm})$, then the outer part of the rib cartilage was taken and diced into small cubes $(0.7 \mathrm{~mm}-1 \mathrm{~mm})$. Then the diced cartilage was wrapped by the rectus fascia. This combination of the diced cartilage and fascia gives the graft its unique characteristics; Strong, smooth, camouflage effect, long standing, and the natural look.

\section{Remnants of the sliced rib cartilage graft wrapped in rectus fascia:-}

This technique is similar to the diced cartilage in rectus fascia

Dr. Mohamed Saad - notice that by slicing the cartilage, it will lose its strength and it is weaker than the core of the cartilage when used as spreader and strut graft, so revision was done to the two cases by using conchol cartilage to strength the tip support.

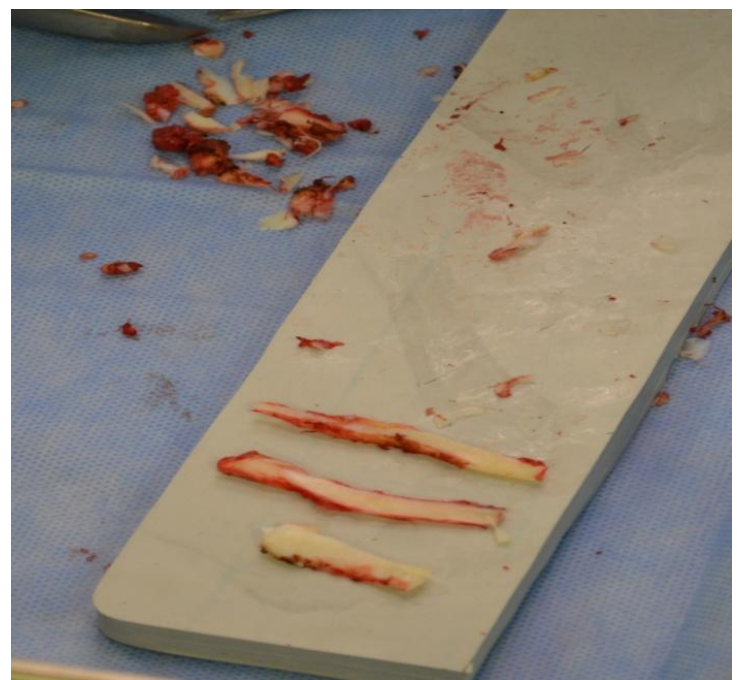

\section{Results:-}

In this study 18 cases have been included, 8 (44.4\%) male patients and $10(55.6 \%)$ female patients. All of them are Middle East patients.

They are presented with different presentation; majority of them had dorsal irregularity (77.8\%) and deviated nose $(66.7 \%)$. Other presentation includes saddle nose $(50 \%)$, radix depression $(27.8 \%)$.

Pre and post-operative nasal lines have been measured, Intra pupillary line has been fixed at $30 \mathrm{~mm}$, and then all other nasal lines (Basal, Dorsal, and Interdomal line) have been measured pre and post-operative, and they all show a significant $P$ values.

Table 1:- Demographic and pre-operative presentation

\begin{tabular}{|l|l|l|}
\hline & Number & Percentage \\
\hline Gender: & & \\
Male & 8 & 44.4 \\
Female & 10 & 55.6 \\
Total & 18 & 100 \\
\hline Smokers & 1 & 5.6 \\
\hline
\end{tabular}




\begin{tabular}{|l|l|l|}
\hline Hyposomnia & 10 & 55.6 \\
\hline Headache & 9 & 50 \\
\hline Sinusitis & 4 & 22.2 \\
\hline
\end{tabular}

Table 2:- Nose Deformity

\begin{tabular}{|l|l|l|}
\hline & Number & Percentage \\
\hline Radix depression & 5 & 27.8 \\
\hline Saddle nose & 9 & 50 \\
\hline Dorsal irregularity & 14 & 77.8 \\
\hline Deviated nose & 12 & 66.7 \\
\hline
\end{tabular}

Table 3:- post-operative complications

\begin{tabular}{|l|l|l|}
\hline & Numbers & Percentage \\
\hline Dorsal irregularity & 2 & 11.1 \\
\hline Seroma & 0 & 16.7 \\
\hline Scars & 4 & 22.2 \\
\hline Septal perforation & 1 & 5.6 \\
\hline
\end{tabular}

None of the 18 cases had other complications; infection, bleeding, nasal obstruction ...etc

Pre-operative basal line, Mean \pm SD $(12.6 \pm 2.7)$. And post-operative measurements are Mean \pm SD $(11.4 \pm 2.7)$, the $\mathrm{p}$ value is 0.004 which is statically significant. Pre-op Dorsal line, Mean \pm SD (5.8 \pm 1.4$)$. And Post-op Dorsal line,

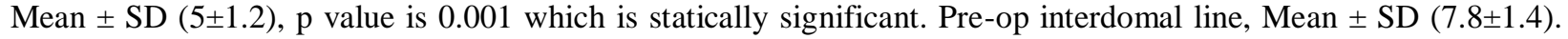
Post-op interdomal line, Mean \pm SD $(7.1 \pm 1.3)$, the $\mathrm{P}$ value is 0.009 which is statically significant.

Table 4:- pre and post operative nasal lines measurements

\begin{tabular}{|l|l|l|l|l|l|l|}
\hline & \multicolumn{2}{l|}{} & \multicolumn{2}{l|}{ Interdomal line } \\
\hline & Basal line & Porsal line & Pre & Post & Pre & Post \\
\hline Mean \pm & $12.6 \pm$ & $11.4 \pm 2.7$ & $5.8 \pm 1.4$ & $5 \pm 1.2$ & $7.8 \pm 1.4$ & $7.1 \pm 1.3$ \\
\hline P value & 0.004 & 0.001 & & 0.009 & \\
\hline
\end{tabular}

Regarding the nasal angles (Nasofrontal, Nasolipial angle, and Tip deviation) have been measured pre and postoperative as well. And for all the angles, their P Values are statistically significant.

Pre-op Nasofrontal angle, Mean \pm SD (144.4 \pm 7.9). Post-op Nasofrontal angle, Mean \pm SD (135 \pm 7.8$)$. P value is < 0.001 which is significant. Pre-op Nasolipial angle, Mean \pm SD $(86.4 \pm 9.5)$. Post-op Nasolipial angle, Mean \pm SD (97.9 \pm 7.7). $\mathrm{P}$ value is $<0.001$ which is significant. Pre-op tip deviation, Mean \pm SD (1.9 \pm 2.3$)$. Post-op tip deviation, Mean \pm SD $(0.47 \pm 0.73)$.

Table 6:- pre and post operative angles measurements

\begin{tabular}{|l|l|l|l|l|l|l|}
\hline & Nasofrontal angel & \multicolumn{2}{l|}{ Nasolipial angel } & \multicolumn{2}{l|}{ Tip deviation } \\
\hline & Pre & Post & Pre & Post & Pre & Post \\
\hline Mean \pm SD & $144.4 \pm 7.9$ & $135 \pm 7.8$ & $86.4 \pm 9.5$ & $97.9 \pm 7.7$ & $1.9 \pm 2.3$ & $0.47 \pm 0.73$ \\
\hline P value & $<0.001$ & $<0.001$ & & \\
\hline
\end{tabular}

The patient's satisfactions regarding breathing and Aesthetic look have been included in the study. There was dramatically improvement in both breathing and cosmetic appearance. Breathing and Aesthetic P values are less than 0.001 which are statistically significant.

Table 5:- satisfaction

\begin{tabular}{|l|l|l|l|l|}
\hline \multicolumn{2}{|l|}{ Breathing } & Aesthetic & Post \\
\hline & Pre & Post & Pre & $4.7 \pm 0.5$ \\
\hline Mean \pm & $2.3 \pm 0.8$ & $4.9 \pm 0.5$ & $1.8 \pm 0.7$ & $<0.001$ \\
\hline P value & $<0.001$ & & \\
\hline
\end{tabular}

None of the patients had Diabetes, Hypertension, or other co-morbidities.

All patients removed their sutures after 7 days of surgery, and they all received oral antibiotics and analgesics after surgery. The follow-up of all 18 cases have been done at least 12 months post-operative.

\section{Discussion:-}

The main goal of septorhinoplasty is to achieve the optimal functional and aesthetic results, regarding the patient and surgeon prevalence. Autogenous costal cartilage graft is the graft of choice in revision septorhinoplasty [1, 2]. Costal 
cartilage graft provides the adequate amount of tissue needed to reconstruct the defected cartilages, and has low rate of absorption [2]. Some complications have been noted, and to avoid those complications multiple techniques are used [5]. Knowing which method is better is mandatory as the use of costal cartilage graft become the standard of care in revision septorhinoplasty $[2,5]$. The costal cartilage graft has been used in deferent techniques. 16 out of 18 cases have been done by taking the outer side of the cartilage graft, then diced and wrapped in rectus muscle ( 8 cases), and temporalis fascia ( 7 cases). The other two cases have been done by taking the costal cartilage in a slices technique, this used for spread and strut graft, and then the remnants diced and wrapped in rectus fascia. One case has been done using the cartilage alone without Dicing, and this has the lowest results of all of them. The best technique was the diced cartilage with rectus fascia because it harvests the fasciae and rib from the same site and no need for another incision to harvest the temporalis muscle fascia.

The result depends on three main factors, patient satisfaction, nasal measurements (angels and lines), and post operative complication.

Patient satisfactions in function (breathing) and aesthetic look were taken pre and one year post operative. All the patients are satisfied with the result.

Regarding the nasal measurements, the goal was to reduce the nasofrontal angel to the range between 115 -135 degree. And to increase the Nasolabial angel to the range between 90-95 in males, and 95-105 in females. Both angels have significant $P$ value.

None of the patients developed significant post operative complication, except slices technique, we did for him augmentation of the lower lateral cartilage with chonchal cartilage graft to support the tip.

\section{Advantages of our research:-}

18 cases were obtained from January 2011 to December 2016 in KAMC center with an inclusion criteria involved both primary and revision septorhinoplasty. All patients complain of function and structural defect, Cosmetic cases were excluded from the research. Adult patient were only selected with 10 female and 8 male patients. Rib cartilage graft used in all patients with different techniques involved: Core cartilage, slices and diced cartilage wrapped in either temporal or rectus muscle fascia. Objective and subjective measurement were done for the patients before and after operation with follow up duration post operatively for at least one year and complication documented if present.

The difficulties we faced in our research which include cases were obtained from KAMC only and that reflected the low number of cases. In future research we will include multiple centers to increase the number of data involved to get more accurate results.

\section{Conclusion:-}

We conclude that autogenous rib cartilage grafts are an outstanding material in septorhinoplasty when structural, functional, and aesthetic problems are present.

Autogenous rib cartilage grafts are the gold standard for nasal reconstruction in patients with cartilage depletion and when large amount of cartilage are needed.

Autogenous costal cartilage grafting offers strength for nasal support to replace or augment missing tissue.

\section{Reference:-}

1. Calvert, Jay W., Anita C. Patel, and Rollin K. Daniel. "Reconstructive Rhinoplasty: Operative Revision of Patients with Previous Autologous Costal Cartilage Grafts." Plastic and reconstructive surgery 133.5 (2014): 1087-1096.

2. Moretti, A., and S. Sciuto. "Rib grafts in septorhinoplasty." Acta Otorhinolaryngologica Italica 33.3 (2013): 190.

3. Bussi, M., F. Palonta, and S. Toma. "Grafting in revision rhinoplasty." Acta Otorhinolaryngologica Italica 33.3 (2013): 183.

4. Park, Joo Hyun, and Hong Ryul Jin. "Use of autologous costal cartilage in Asian rhinoplasty." Plastic and reconstructive surgery 130.6 (2012): 1338-1348.

5. Daniel, Rollin K., and Jay W. Calvert. "Diced cartilage grafts in rhinoplasty surgery." Plastic and reconstructive surgery 113.7 (2004): 2156-2171.

6. Kridel, Russell WH, et al. "Long-term use and follow-up of irradiated homologous costal cartilage grafts in the nose." Archives of facial plastic surgery 11.6 (2009): 378-394. 